\title{
Modes of mechanical ventilation vary between hospitals and intensive care units within a university healthcare system: a retrospective observational study
}

\author{
Craig S. Jabaley ${ }^{1,2^{*}}$, Robert F. Groff ${ }^{1,2}$, Milad Sharifpour ${ }^{1}$, Jayashree K. Raikhelkar ${ }^{1,2}$ and James M. Blum ${ }^{1,2,3}$
}

\begin{abstract}
Objective: As evidence-based guidance to aid clinicians with mechanical ventilation mode selection is scant, we sought to characterize the epidemiology thereof within a university healthcare system and hypothesized that nonconforming approaches could be readily identified. We conducted an exploratory retrospective observational database study of routinely recorded mechanical ventilation parameters between January 1, 2010 and December 31, 2016 from 12 intensive care units. Mode epoch count proportions were examined using Chi squared and Fisher exact tests as appropriate on an inter-unit basis with outlier detection for two test cases via post hoc pairwise analyses of a binomial regression model.

Results: Final analysis included 559,734 mode epoch values. Significant heterogeneity was demonstrated between individual units ( $P<0.05$ for all comparisons). One unit demonstrated heightened utilization of high-frequency oscillatory ventilation, and three units demonstrated frequent synchronized intermittent mandatory ventilation utilization. Assist control ventilation was the most commonly recorded mode (51\%), followed by adaptive support ventilation (23.1\%). Volume-controlled modes were about twice as common as pressure-controlled modes (64.4\% versus 35.6\%). Our methodology provides a means by which to characterize the epidemiology of mechanical ventilation approaches and identify nonconforming practices. The observed variability warrants further clinical study about contributors and the impact on relevant outcomes.
\end{abstract}

Keywords: Positive pressure ventilation, Respiratory failure, Mechanical ventilators, Noninvasive ventilation, Ventilator weaning, Intensive care

\section{Introduction}

Relatively scant evidence exists to guide clinicians in their selection of a mechanical ventilation (MV) mode. International epidemiological studies have identified that tidal volume $(\mathrm{Vt})$, positive end-expiratory pressure (PEEP), and other parameters are beginning to align with lung protective ventilation strategies [1-4]. These and other characterizations of MV mode selection are variable in their scope, often examining only certain modes

\footnotetext{
*Correspondence: csjabaley@emory.edu

1 Division of Critical Care Medicine, Department of Anesthesiology, Emory University, 1364 Clifton Road NE, Atlanta, GA 30322, USA

Full list of author information is available at the end of the article
}

or patient subsets, and a clear picture of practice patterns remains elusive [5-21].

Developing a means by which to assess variability in the approach to MV offers an opportunity to identify outlying or nonconforming practices for which educational, quality improvement, or other such interventions could be appropriate [22]. For example, routine use of high-frequency oscillatory ventilation (HFOV) and synchronized intermittent mandatory ventilation (SIMV) have been called into question. Two prospective studies of HFOV demonstrated largely equivalent outcomes in patients with acute respiratory distress syndrome, and 
SIMV has been associated with delayed separation from MV [23-28].

In light of multiple barriers to the consistent and evidence-based selection of a MV mode, we sought to characterize the epidemiology of MV mode selection within four hospitals affiliated with a university healthcare system. We hypothesized that this approach could identify outlying or nonconforming approaches to MV, specifically the provision of HFOV and SIMV as test cases. Furthermore, we aimed to characterize variability between ICUs that treat similar patient populations and identify, if present, any consistent patterns between types of ICUs and between individual ICUs across hospitals in support of subsequent hypothesis generation.

\section{Main text \\ Methods \\ Study design}

We conducted an exploratory retrospective observational database study of routinely collected MV parameters to examine mode utilization in 12 adult ICUs across four hospitals between January 1, 2011 and December 31, 2016. Condensed reporting herein follows the Strengthening the Reporting of Observational Studies in Epidemiology statement and the Reporting of Studies Conducted Using Observational Routinely Collected Health Data statements where applicable [29, 30]. Approval was granted by the Emory University Institutional Review Board (ID \#IRB00095006) with a waiver of informed consent owing to its retrospective design.

\section{Setting and source population}

Twelve ICUs in four standalone hospitals affiliated with Emory Healthcare (Atlanta, GA USA) were studied, which comprised 191/237 critical care beds, or $80.6 \%$ of the system wide total. We categorized ICUs by their primary mission whereby a: (a) cardiothoracic surgical ICU (CTICU) treats patients after major heart, lung, and vascular surgery; (b) neuroscience ICU (NSICU) treats patients following cerebrovascular insults and intracranial procedures; (c) surgical ICU (SICU) treats postoperative patients not in one of the two prior categories, (d) medical ICU (MICU) treats critically ill adults not having recently undergone surgery, and (e) medical-surgical ICU (MSICU) treats a mixture of critically ill adults. The studied ICUs vary in their format and staffing (see Additional file 1: Table S1 for further details) [31, 32]. Ventilator management is the responsibility of the critical care physician, or the admitting physician in ICUs without critical care staffing. MV equipment has changed across the system during the study period with increasing availability of Hamilton (Hamilton Medical AG, Bonaduz, Switzerland) ventilators (e.g. Galileo, G3, and G5) and a gradual reduction in Puritan Bennett (Covidien LP, Boulder, CO, USA) models (e.g. 840) as a result of standardization efforts.

\section{Data sources}

MV parameters and settings, including mode, are routinely charted every $4 \mathrm{~h}$ in the electronic medical record (EMR), or immediately following a setting change, by respiratory therapists (RTs). EMR documentation is consolidated nightly into the Clinical Data Warehouse (CDW) via an extract, transform, and load process, which has been internally validated by Information Services. The CDW is indexed to support advanced analytics and is accessed via structured query language and MicroStrategy (MicroStrategy Inc., Washington, DC, USA) interfaces.

\section{Structured query approach}

Each instance of recorded MV parameters was considered a stand-alone epoch and extracted from the CDW on a per-epoch, per-ICU basis during the period of interest and then imported into MariaDB (MariaDB Corporation $A B$, Espoo, Finland). No database linking was required. MariaDB was used to aggregate the data and identify nonsensical (e.g. numerical) values, which were excluded from analysis. Data cleaning consisted of identification and removal of elements with typographical errors (e.g. letter transposition and misspelling), which were rare as the EMR relies heavily on pre-populated dropdown charting for MV mode. The two NSICUs in Hospital 1 were considered in aggregate for inter-unit comparisons as they are managed by the same critical care team. Reported epoch counts represent all those recorded during the period of interest.

\section{Statistical analysis}

Proportions of routinely recorded nominal categorical mode counts were generated and initially visualized in SAS JMP Pro version 13.1.0 (SAS Institute Inc., Cary, NC, USA). Final analysis was done with $\mathrm{R}$ version 3.4.4 (R Core Team, Vienna, Austria) in RStudio 1.1.453 (RStudio Inc, Boston, MA, USA). Pearson's Chi square test for overall homogeneity was run prior to further comparisons. Sub-analyses of nominal categorical MV mode count proportions were conducted using Chi square or Fisher's exact test as appropriate on an inter-ICU basis. Modes accounting for less than $2 \%$ of per-unit epochs were excluded from this analysis as they may be less clinically significant. Outlying proportions of HFOV and SIMV (both pressure- and volume-controlled variants) as test cases were initially identified through examination of standardized residuals. These were confirmed via binomial regression with post hoc comparison of 
least-squares means and Bonferroni corrected pairwise comparisons to examine inter-ICU variability. $\mathrm{P}$ values $<0.05$ were considered significant. Given the limited dataset and goals of the study, characterization of demographic variables and attempts to control for bias or confounding were beyond the scope of the investigation. Figures were generated using the ggplot2 and RColorBrewer packages [33].

\section{Results}

The CDW query identified 559,762 recorded MV epochs from the ICUs of interest between January 1, 2011 and December 31, 2016. Of those, the MV mode values for 28 epochs $(0.005 \%)$ were nonsensical and excluded from analysis (Additional file 2: Figure S1). Mode epoch frequencies were significantly heterogeneous between individual ICUs as depicted with aggregate counts in Fig. 1 and proportions in Fig. 2 (Table $1, \mathrm{P}<0.05$ for all comparisons). Heterogeneity was therefore evident between like types of ICU (Additional file 3: Table S2) as depicted proportionally on a per-unit basis in Additional file 4: Figure S2 and aggregated in Additional file 5: Figure S3. Similar variability was evident when aggregating units by hospital as depicted proportionally in Additional file 6: Figure $\mathrm{S} 4$.

HFOV utilization was found to be nonconforming in single MICU in Hospital 1, which accounted for $40.9 \%$ of system wide epochs $(\mathrm{P}<0.001$ for all pairwise comparisons). Three ICUs similarly accounted for a disproportionate proportion of overall SIMV utilization: Hospital 3 CTICU with $48.4 \%$ of epochs $(\mathrm{N}=14,049 / 29,001)$, Hospital 3 MSICU with $26.8 \%(\mathrm{~N}=7769 / 29,001)$, and Hospital 1 CTICU with $14.5 \%(\mathrm{~N}=4209 / 29,001$; adjusted $\mathrm{P}<0.001$ for all pairwise comparisons).

Hospital 1 accounted for $51.3 \%$ of total recorded MV mode epochs $(\mathrm{N}=287,026 / 559,734)$. Assist control (AC) was the most commonly recorded MV mode overall $(\mathrm{N}=285,669 / 559,734,51 \%)$ followed by adaptive

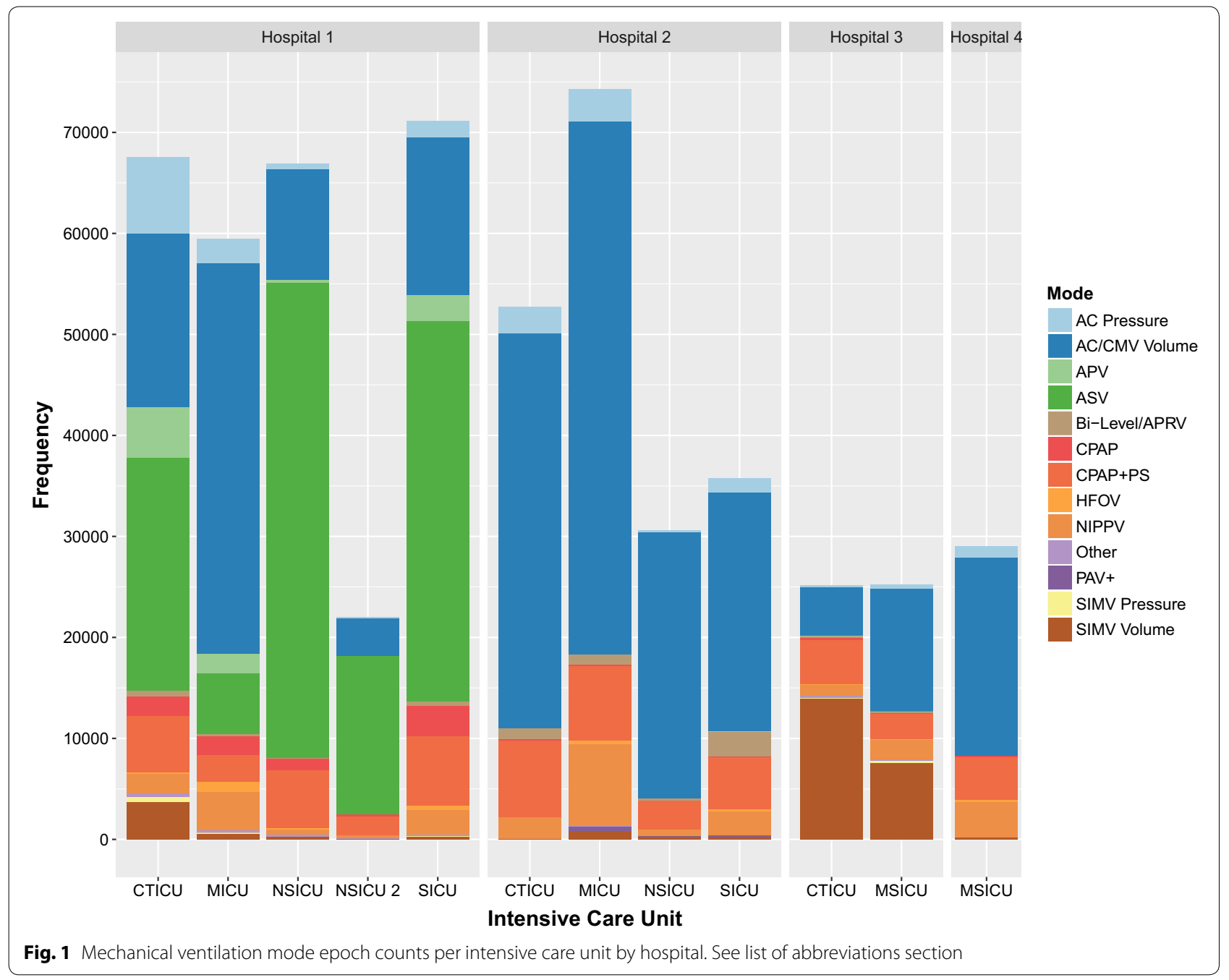




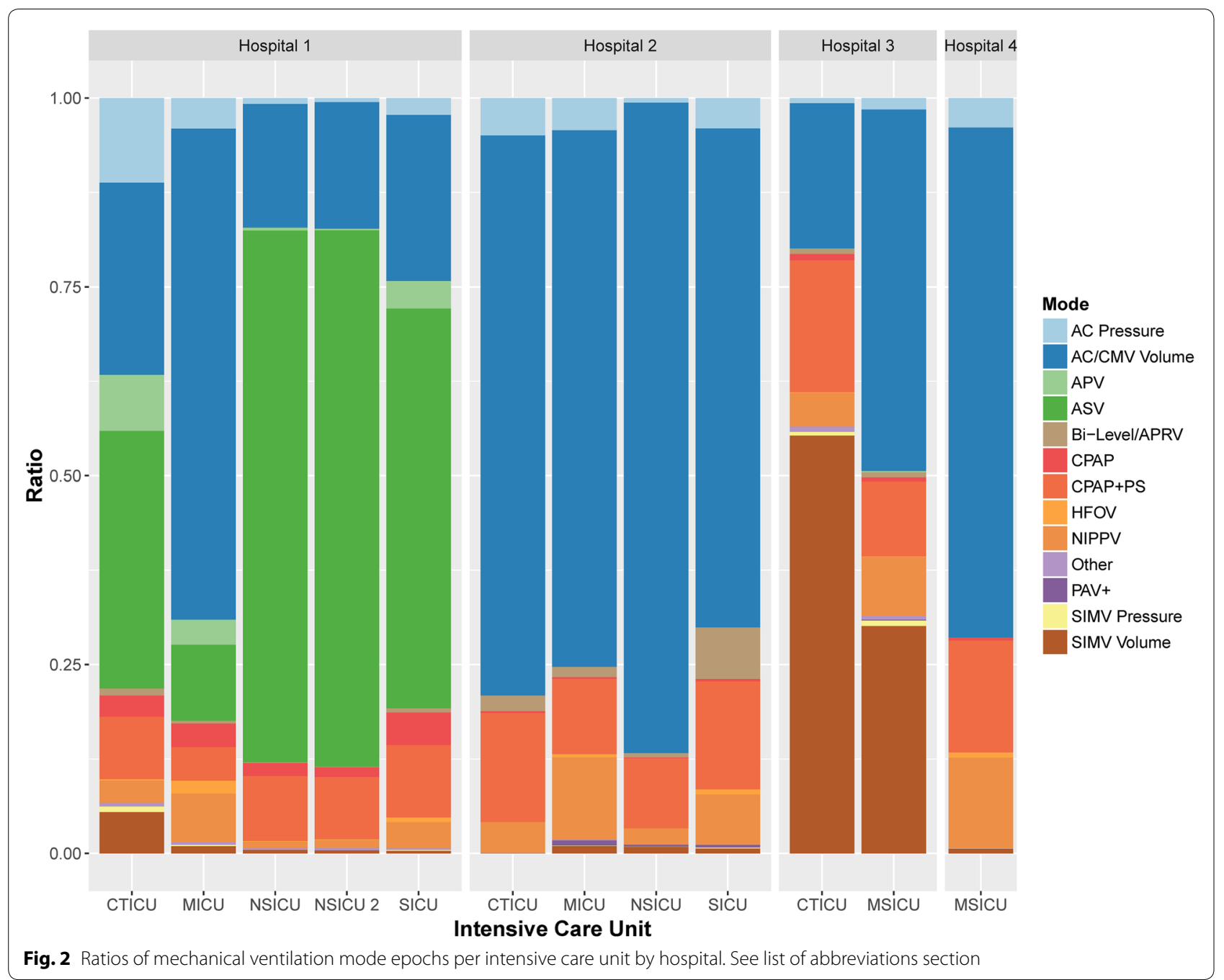

support ventilation (ASV, $\mathrm{N}=129,341 / 559,734,23.1 \%$ ), and pressure support ventilation (PSV, i.e. continuous positive airway pressure with pressure support [CPAP with PS], $\mathrm{N}=56,822 / 559,734,10.2 \%)$. When examining AC, SIMV, adaptive pressure ventilation (APV), and considering ASV to be a pressure-controlled mode for passive patients, the overall prevalence of invasive pressure controlled modes of ventilation was 35.6\% $(\mathrm{N}=161,627 / 453,977)$ compared to $64.4 \%$ for volume controlled modes $(\mathrm{N}=292,350 / 453,977)$. In examining graphical comparisons, the two studied MICUs demonstrated the most consistent approach to mode selection when examining like-type ICUs (Additional file 4: Figure S2.) Within individual hospitals with greater than one ICU, units in Hospital 2 were the most consistent (Fig. 2).

\section{Discussion}

Mode epoch proportions were significantly heterogeneous between individual ICUs, contributing to variability on an aggregate basis. Outlying utilization of HFOV in one ICU and SIMV in three suggests that this approach can be utilized to identify potentially nonconforming practice patterns. Only one hospital demonstrated a relatively consistent distribution of MV modes across its studied ICUs, and the two studied MICUs were most similar to one another; however, there were still statistically significant differences.

Nonconforming MV mode utilization was readily identified, and our approach may be able, more broadly, to identify other clinically outlying or inappropriate MV parameter selections. Utilization of HFOV appeared to be rare, which aligns with findings from large prospective 


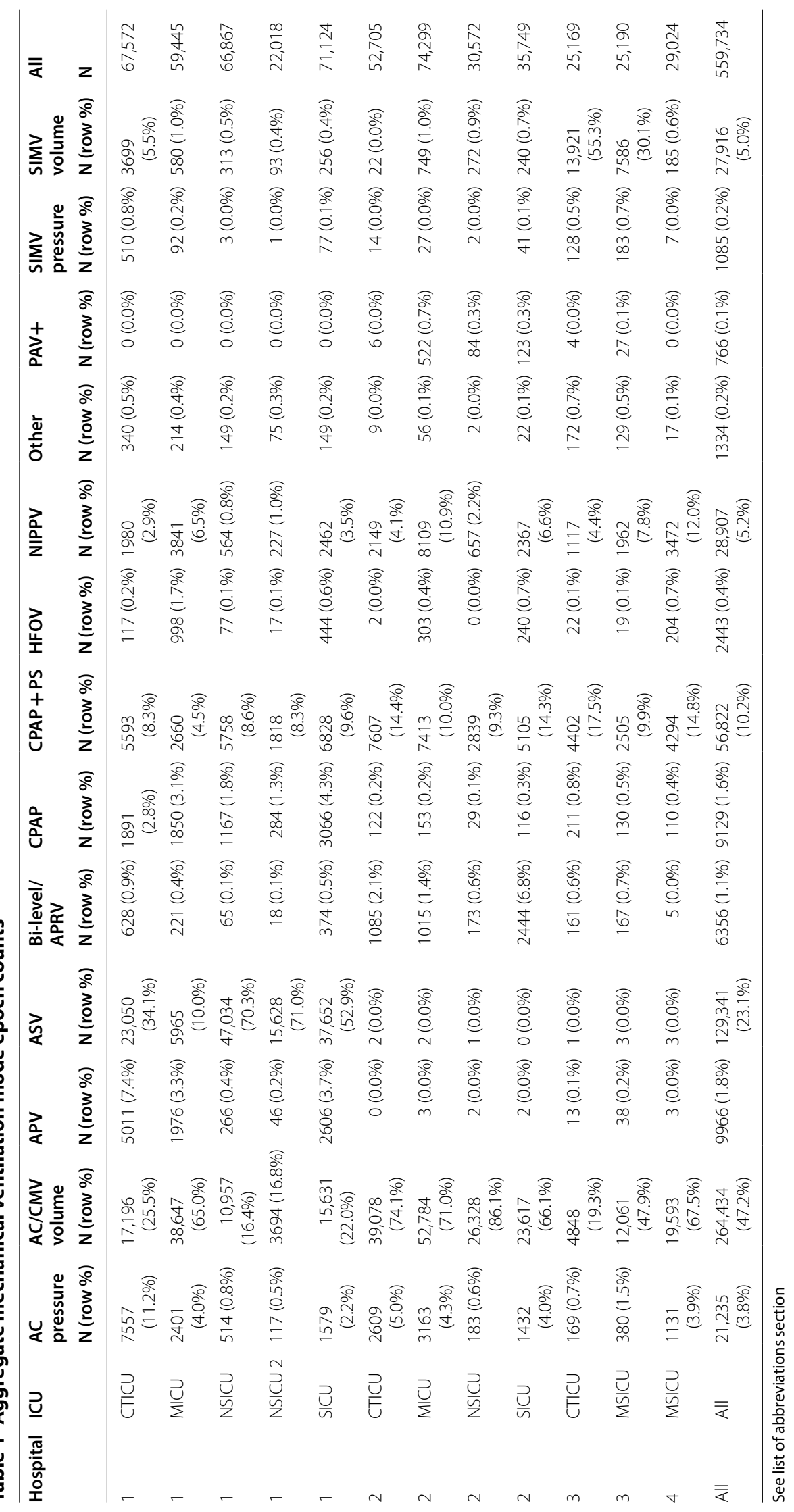


studies suggesting equivalent clinical outcomes with greater risks than more conventional forms of MV [23, 24]. Overall utilization of SIMV was lower than the $26 \%$ rate reported in a recent large observational study, although we were able to identify outlying units [3]. Its routine application as a weaning modality has been questioned, and global utilization may be experiencing an associated decline [25-28, 34].

In keeping with prior studies demonstrating an approximate utilization rate of $50-60 \%, \mathrm{AC}$ was likewise found to be the most frequently recorded mode of ventilation in our healthcare system $[5,6,13,35]$. Recent international MV practice studies have, however, suggested that novel modes may be gradually driving a move away from AC toward closed-loop approaches [3]. Volume-controlled ventilation was about twice as common as pressurecontrolled ventilation, which is in contrast to a recent international epidemiological study demonstrating the opposite [3]. From a speculative standpoint, this could reflect an emphasis on monitoring of $\mathrm{Vt}$, greater ease of $\mathrm{Vt}$ restriction with volume-controlled modes, mischarting of volume-targeted pressure-controlled modes, or physician preference as no definitive difference in compliance, gas exchange, or outcomes has been demonstrated [36].

As discussed subsequently, limited inferences can be drawn about weaning approaches. Although one hospital demonstrated marked adoption of ASV, proportional assist ventilation (PAV) was very uncommon, which may suggest heterogeneity in the willingness to adopt closedloop MV modes consistent with the findings of other epidemiological studies [3]. PSV was utilized relatively consistently across the system and in excess of CPAP alone, which is consistent with current $\mathrm{MV}$ weaning guidelines [37].

\section{Limitations}

Our study has important limitations. Owing to its retrospective nature and use of a limited dataset, both unmeasured confounding with associated confounding bias and indication bias preclude inferences as to the etiology of heterogeneity, which may have been clinically appropriate. Rather, posited causes of heterogeneity herein are purely speculative. Staffing, equipment, patient-specific considerations, or any number of other factors may influence MV mode selection. Attempts to control for bias or confounding were beyond the scope of our epidemiological study, and these considerations limit generalizability of the findings.

Owing to our methodologic approach, we were unable to determine the duration or time sequence of specific MV modes utilization. As a simple example, although MV charting is consistent every $4 \mathrm{~h}$ or with changes, a patient on $\mathrm{AC}$ for $3 \mathrm{~h}$ and PSV for one would have a single AC and PSV epoch recorded. As such, the actual AC:PSV time ratio of $3: 1$ would appear to be $1: 1$ via this study's methodology. This limits the inferences that can be drawn about approaches to ventilator separation and weaning.

As with any study that relies on routinely collected data, inaccurate bedside charting cannot be excluded. The incidence of nonsensical MV mode values was very low, likely owing to the EMR's use of predefined MV mode selections. In that sense, our nominal categorical data may be more accurate than similarly recorded ordinal data. However, the potential for information bias cannot be excluded. For example, pressure-controlled volume-targeted AC modes could conceivably be charted incorrectly.

The highly heterogeneous nature of MV mode distribution found in the current study suggests that mode selection likely involves a complex interplay of factors, which could include institution, ICU, or provider-specific considerations in addition to patient or disease-related factors. The relationship between MV mode selection, MV parameters (e.g. Vt, PEEP, plateau pressure, or driving pressure), and clinical outcomes also warrants further investigation, especially as approaches to mode selection appear highly variable.

\section{Additional files}

Additional file 1: Table S1. Details of studied hospitals and intensive care units.

Additional file 2: Figure S1. CONSORT flow diagram.

Additional file 3: Table S2. Mechanical ventilation mode epochs per intensive care unit type.

Additional file 4: Figure S2. Ratios of mechanical ventilation mode epochs per hospital by intensive care unit type. Hospital 1 NSICUs depicted in aggregate. See list of abbreviations section.

Additional file 5: Figure S3. Ratios of mechanical ventilation mode epochs per intensive care unit type. See list of abbreviations section.

Additional file 6: Figure S4. Ratios of mechanical ventilation mode epochs per hospital. See list of abbreviations section.

\section{Abbreviations}

AC: assist control; APRV: airway pressure release ventilation; APV: adaptive pressure ventilation; ASV: adaptive support ventilation; CDW: Clinical Data Warehouse; CMV: continuous mandatory ventilation; CPAP: continuous positive airway pressure; CPAP + PS: continuous positive airway pressure with pressure support (i.e. pressure support ventilation [PSV]); CTICU: cardiothoracic intensive care unit; EMR: electronic medical record; HFOV: high frequency oscillatory ventilation; ICU: intensive care unit; MICU: medical intensive care unit; MSICU: medical-surgical intensive care unit; MV: mechanical ventilation; NIPPV: non-invasive positive pressure ventilation; NSICU: neuroscience intensive care unit; PAV: proportional assist ventilation; PEEP: positive end-expiratory pressure; Pplat: plateau pressure; PS: pressure support; PSV: pressure support ventilation; RT: respiratory therapist; SICU: surgical intensive care unit; SIMV: synchronized intermittent mandatory ventilation. 


\section{Authors' contributions}

All authors meet criteria for authorship under ICMJE criteria. JMB conceived the study with critical input from CSJ and RFG. JMB developed and conducted the structured data queries with assistance from CSJ and RFG. CSJ and JMB designed and implemented the analysis plan with input from RFG. RFG, MS, and JKR critically reviewed the analysis plan and results. CSJ wrote the manuscript with critical revisions and conceptual advice from RFG, MS, JKR, and JMB. All authors read and approved the final manuscript.

\section{Author details}

1 Division of Critical Care Medicine, Department of Anesthesiology, Emory University, 1364 Clifton Road NE, Atlanta, GA 30322, USA. ${ }^{2}$ Division of Critical Care Medicine, Anesthesiology Service Line, Atlanta Veterans Affairs Medical Center, Decatur, GA, USA. ${ }^{3}$ Department of Biomedical Informatics, Emory University School of Medicine, Atlanta, GA, USA

\section{Acknowledgements}

Preliminary findings were previously presented at the International Anesthesia Research Society and Society of Critical Care Anesthesiologists 2017 annual meetings in Washington, DC, USA.

\section{Competing interests}

The authors declare that they have no competing interests. JMB has an equity stake in Intensix (Netanya, Israel)

\section{Availability of data and materials}

The datasets used and analyzed during the current study are available from the corresponding author on reasonable request. Aggregate counts are presented in Table 1.

\section{Consent for publication}

Not applicable.

\section{Ethics approval and consent to participate}

Approval for the study was granted by the Emory University Institutional Review Board (ID \#IRB00095006). A waiver of informed consent was granted owing to the retrospective nature of the study and use of de-identified data.

\section{Funding}

Internal departmental funds were used to support the authors'time to conduct the present study.

\section{Publisher's Note}

Springer Nature remains neutral with regard to jurisdictional claims in published maps and institutional affiliations.

Received: 19 March 2018 Accepted: 26 June 2018

Published online: 03 July 2018

\section{References}

1. Bellani G, Laffey JG, Pham T, Fan E, Brochard L, Esteban A, et al. Epidemiology, patterns of care, and mortality for patients with acute respiratory distress syndrome in intensive care units in 50 countries. JAMA 2016;315(8):788-800.

2. Metnitz PGH, Metnitz B, Moreno RP, Bauer P, Sorbo LD, Hoermann C, et al. Epidemiology of mechanical ventilation: analysis of the SAPS 3 database. Intensive Care Med. 2009;35(5):816-25.

3. Neto AS, Barbas CSV, Simonis FD, Artigas-Raventos A, Canet J, Determann RM, et al. Epidemiological characteristics, practice of ventilation, and clinical outcome in patients at risk of acute respiratory distress syndrome in intensive care units from 16 countries (PRoVENT): an international, multicentre, prospective study. Lancet Respir Med. 2016:4(11):882-93.

4. Wunsch H, Linde-Zwirble WT, Angus DC, Hartman ME, Milbrandt EB, Kahn JM. The epidemiology of mechanical ventilation use in the United States. Crit Care Med. 2010;38(10):1947-53.

5. Esteban A, Anzueto A, Frutos F, Alia I, Brochard L, Stewart TE, et al. Characteristics and outcomes in adult patients receiving mechanical ventilation: a 28-day international study. JAMA. 2002;287(3):345-55.
6. Hong SB, Oh BJ, Kim YS, Kang EH, Kim CH, Park YB, et al. Characteristics of mechanical ventilation employed in intensive care units: a multicenter survey of hospitals. J Korean Med Sci. 2008;23(6):948-53.

7. Jeong B-H, Suh GY, An JY, Park MS, Lee JH, Lee M-G, et al. Clinical demographics and outcomes in mechanically ventilated patients in Korean intensive care units. J Korean Med Sci. 2014;29(6):864-70.

8. Ye $Y$, Zhu $B$, Jiang $L$, Jiang $Q$, Wang $M$, Hua $L$, et al. A contemporary assessment of acute mechanical ventilation in Beijing: description, costs, and outcomes. Crit Care Med. 2017:45(7):1160-7.

9. Wenstedt EFE, De Bie Dekker AJR, Roos AN, Verberne JJM, Korsten HHM, Schultz MJ, et al. Current practice of closed-loop mechanical ventilation modes on intensive care units - a nationwide survey in the Netherlands. Neth J Med. 2017;75(4):145-50.

10. Rose L, Blackwood B, Egerod I, Haugdahl HS, Hofhuis J, Isfort M, et al. Decisional responsibility for mechanical ventilation and weaning: an international survey. Crit Care. 2011;15(6):R295.

11. Esteban A, Ferguson ND, Meade MO, Frutos-Vivar F, Apezteguia C, Brochard $\mathrm{L}$, et al. Evolution of mechanical ventilation in response to clinical research. Am J Respir Crit Care Med. 2008;177(2):170-7.

12. Esteban A, Frutos-Vivar F, Muriel A, Ferguson ND, Penuelas O, Abraira V, et al. Evolution of mortality over time in patients receiving mechanical ventilation. Am J Respir Crit Care Med. 2013;188(2):220-30.

13. Esteban A, Anzueto A, Alía I, Gordo F, Apezteguía C, Pálizas F, et al. How is mechanical ventilation employed in the intensive care unit? Am J Respir Crit Care Med. 2000;161(5):1450-8.

14. Kübler A, Maciejewski D, Adamik B, Kaczorowska M. Mechanical ventilation in ICUs in Poland: a multi-center point-prevalence study. Med Sci Monit. 2013;19:424-9.

15. Esteban A, Alia I, Ibanez J, Benito S, Tobin MJ. Modes of mechanical ventilation and weaning. A national survey of Spanish hospitals. The Spanish Lung Failure Collaborative Group. Chest. 1994;106(4):1188-93.

16. Koh Y, Lim CM, Koh SO, Ahn JJ, Kim YS, Jung BH, et al. A national survey on the practice and outcomes of mechanical ventilation in Korean intensive care units. Anaesth Intensive Care. 2009;37(2):272-80.

17. Rose L, Presneill JJ, Johnston L, Nelson S, Cade JF. Ventilation and weaning practices in Australia and New Zealand. Anaesth Intensive Care. 2009;37(1):99-107.

18. Demoule A, Chevret S, Carlucci A, Kouatchet A, Jaber S, Meziani F, et al. Changing use of noninvasive ventilation in critically ill patients: trends over 15 years in francophone countries. Intensive Care Med. 2016;42(1):82-92.

19. Antonelli M, Conti G, Esquinas A, Montini L, Maggiore SM, Bello G, et al. A multiple-center survey on the use in clinical practice of noninvasive ventilation as a first-line intervention for acute respiratory distress syndrome. Crit Care Med. 2007;35(1):18-25

20. Bellani G, Laffey JG, Pham T, Madotto F, Fan E, Brochard L, et al. Noninvasive ventilation of patients with acute respiratory distress syndrome. Insights from the LUNG SAFE study. Am J Respir Crit Care Med. 2017:195(1):67-77.

21. Walkey AJ, Wiener RS. Use of noninvasive ventilation in patients with acute respiratory failure, 2000-2009: a population-based study. Ann Am Thorac Soc. 2013;10(1):10-7.

22. Murphy DJ, Lyu PF, Gregg SR, Martin GS, Hockenberry JM, Coopersmith $C M$, et al. Using incentives to improve resource utilization: a quasi-experimental evaluation of an ICU quality improvement program. Crit Care Med. 2016:44(1):162-70.

23. Ferguson ND, Cook DJ, Guyatt GH, Mehta S, Hand L, Austin P, et al. Highfrequency oscillation in early acute respiratory distress syndrome. N Engl Med. 2013;368(9):795-805

24. Young D, Lamb SE, Shah S, MacKenzie I, Tunnicliffe W, Lall R, et al. Highfrequency oscillation for acute respiratory distress syndrome. N Engl J Med. 2013:368(9):806-13.

25. Esteban A, Frutos F, Tobin MJ, Alia I, Solsona JF, Valverdu I, et al. A comparison of four methods of weaning patients from mechanical ventilation. Spanish Lung Failure Collaborative Group. N Engl J Med. 1995:332(6):345-50

26. Brochard L, Rauss A, Benito S, Conti G, Mancebo J, Rekik N, et al. Comparison of three methods of gradual withdrawal from ventilatory support during weaning from mechanical ventilation. Am J Respir Crit Care Med. 1994;150(4):896-903. 
27. Luo J, Wang MY, Liang BM, Yu H, Jiang FM, Wang T, et al. Initial synchronized intermittent mandatory ventilation versus assist/control ventilation in treatment of moderate acute respiratory distress syndrome: a prospective randomized controlled trial. J Thorac Dis. 2015;7(12):2262-73.

28. Ortiz G, Frutos-Vivar F, Ferguson ND, Esteban A, Raymondos K, Apezteguia $C$, et al. Outcomes of patients ventilated with synchronized intermittent mandatory ventilation with pressure support: a comparative propensity score study. Chest. 2010;137(6):1265-77.

29. Benchimol El, Smeeth L, Guttmann A, Harron K, Moher D, Petersen I, et al. The REporting of studies Conducted using Observationa Routinely-collected health Data (RECORD) statement. PLoS Med. 2015;12(10):e1001885.

30. von Elm E, Altman DG, Egger M, Pocock SJ, Gøtzsche PC, Vandenbroucke JP. The Strengthening the Reporting of Observational Studies in Epidemiology (STROBE) statement: guidelines for reporting observational studies. Lancet. 2007;370(9596):1453-7.

31. Grabenkort WR, Meissen HH, Gregg SR, Coopersmith CM. Acute care nurse practitioners and physician assistants in critical care: transforming education and practice. Crit Care Med. 2017;45(7):1111-4.

32. Buchman TG, Coopersmith CM, Meissen HW, Grabenkort WR, Bakshi V, Hiddleson CA, et al. Innovative interdisciplinary strategies to address the intensivist shortage. Crit Care Med. 2017;45(2):298-304
33. Wickham H. ggplot2: elegant graphics for data analysis. New York: Springer; 2009.

34. Kacmarek RM, Branson RD. Should intermittent mandatory ventilation be abolished? Respir Care. 2016;61(6):854-66.

35. Rose L, Schultz MJ, Cardwell CR, Jouvet P, McAuley DF, Blackwood B. Automated versus non-automated weaning for reducing the duration of mechanical ventilation for critically ill adults and children. Cochrane Database Syst Rev. 2014;6:CD009235.

36. Rittayamai N, Katsios CM, Beloncle F, Friedrich JO, Mancebo J, Brochard L. Pressure-controlled vs volume-controlled ventilation in acute respiratory failure: a physiology-based narrative and systematic review. Chest. 2015;148(2):340-55.

37. Ouellette DR, Patel S, Girard TD, Morris PE, Schmidt GA, Truwit JD, et al. Liberation from mechanical ventilation in critically ill adults: an official American College of Chest Physicians/American Thoracic Society clinical practice guideline: inspiratory pressure augmentation during spontaneous breathing trials, protocols minimizing sedation, and noninvasive ventilation immediately after extubation. Chest. 2017;151(1):166-80.
Ready to submit your research? Choose BMC and benefit from:

- fast, convenient online submission

- thorough peer review by experienced researchers in your field

- rapid publication on acceptance

- support for research data, including large and complex data types

- gold Open Access which fosters wider collaboration and increased citations

- maximum visibility for your research: over 100M website views per year

At BMC, research is always in progress.

Learn more biomedcentral.com/submissions 